\title{
Lactoferrin CpG Island Hypermethylation and Decoupling of mRNA and Protein Expression in the Early Stages of Prostate Carcinogenesis
}

Corey M. Porter, * Michael C. Haffner, * Ibrahim Kulac, * Janielle P. Maynard, * Javier A. Baena-Del Valle, * William B. Isaacs, Srinivasan Yegnasubramanian, ${ }^{* \dagger}$ Angelo M. De Marzo, ${ }^{* \dagger}$ and Karen S. Sfanos ${ }^{* \dagger}$

From the Department of Pathology, ${ }^{*}$ the Department of Urology ${ }^{\dagger}$ James Buchanan Brady Urological Institute, and the Sidney Kimmel Comprehensive Cancer Center, ${ }^{\ddagger}$ Johns Hopkins University School of Medicine, Baltimore, Maryland

Accepted for publication

July 25, 2019

Address correspondence to Karen S. Sfanos, M.S., Ph.D., Department of Pathology, Johns Hopkins University School of Medicine, 1550 Orleans St., CRB II Room 143, Baltimore, MD 21287. E-mail: ksfanos@ jhmi.edu.

\begin{abstract}
Lactoferrin (LTF) is an iron-binding protein canonically known for its innate and adaptive immune functions. LTF may also act as a tumor suppressor with antiproliferative action. LTF is inactivated genetically or epigenetically in various cancers, and a CpG island spanning the transcriptional start site of LTF is hypermethylated in prostate cancer cell lines. We, therefore, hypothesized that LTF expression is silenced via $\mathrm{CpG}$ island hypermethylation in the early stages of prostate tumorigenesis carcinogenesis. Targeted methylation analysis was performed using a combination of methylated-DNA precipitation and methylation-sensitive restriction enzymes, and laser-capture microdissection followed by bisulfite sequencing on DNA isolated from prostate tissue samples, including both primary and metastatic disease. LTF mRNA in situ hybridization and LTF protein immunohistochemistry were also performed. We report that the LTF CpG island is frequently and densely methylated in high-grade prostatic intraepithelial neoplasia, primary prostate carcinoma, and metastases. We further report a decoupling of lactoferrin mRNA and protein expression, including in lesions where LTF mRNA has presumably been silenced via $\mathrm{CpG}$ island methylation. We conclude that LTF mRNA expression is silenced in prostate tumorigenesis via hypermethylation, supporting a role for LTF as a prostate cancer tumor suppressor gene. Likewise, the frequency at which the LTF CpG island is methylated across samples suggests it is an important and conserved step in prostate cancer initiation. (Am J Pathol 2019, 189: 2311-2322; https://doi.org/10.1016/j.ajpath.2019.07.016)
\end{abstract}

Inflammation has been implicated in prostate cancer initiation and progression. ${ }^{1-3}$ Although the causative factors driving prostatic inflammation are largely uncertain, chronic inflammation and, to a lesser extent, acute inflammation are common findings in the peripheral and transition zones of the prostate. Of interest, these two zones that have the most inflammation are also the zones most likely to develop disease. The transition zone is the zone most likely to develop benign prostatic hyperplasia (BPH), and the peripheral zone is the zone most likely to develop prostate cancer. Corpora amylacea are small stone-like structures that are frequently found in prostatectomy samples, often in areas of inflammation. It has previously been demonstrated that corpora amylacea are composed of proteins involved in acute inflammatory responses and, in particular, proteins contained in neutrophil granules. ${ }^{4}$ The most abundant of these proteins was the innate immune protein lactoferrin (LTF). LTF is an iron-binding protein in the transferrin family found in secreted fluids, such as breast milk, tears,

\footnotetext{
Supported by the Department of Defense Prostate Cancer Research Program (PCRP) awards W81XWH-14-1-0364 (K.S.S.), W81XWH-18-20013 and W81XWH-18-2-0015 (K.S.S. and A.M.D.); the Prostate Cancer Biorepository Network; and NIH/National Cancer Institute grants P30CA006973 (K.S.S., A.M.D., and S.Y.), P50CA058236 (K.S.S., A.M.D., S.Y.), and U01CA196390 (K.S.S., A.M.D., S.Y.).

Disclosures: None declared.

Current address of I.K., Department of Pathology, Koç University School of Medicine, Istanbul, Turkey; of J.A.B-D.V., Department of Pathology and Laboratory Medicine, Fundacion Santa Fe de Bogota University Hospital, Bogota, Colombia.
} 
sweat, and prostatic fluid. ${ }^{5-7}$ LTF has been shown to reduce inflammation and oxidative stress via its iron-binding abilities. ${ }^{8}$ LTF protein has antimicrobial properties, can initiate an immune response, and protects against the harmful effects of inflammation. ${ }^{8-11}$ LTF protein has also been absent or weakly expressed in benign prostate tissue in the peripheral zone, with a marked increase in areas with inflammation and/or atrophy; and LTF protein is low or absent in prostate cancer. ${ }^{4,12}$

Proliferative inflammatory atrophy, in which atrophic epithelial cells are highly proliferative (apparently in response to cellular damage) and surrounded by inflammatory cells, is a type of atrophy that can be prevalent in the prostates of some men. ${ }^{13}$ These atrophic glands share, at a low frequency, some of the somatic genomic alterations found in prostate cancer and its putative precursor lesion, prostatic intraepithelial neoplasia (PIN). Proliferative inflammatory atrophy lesions also show early evidence of epigenetic changes that are common in prostate cancer. For instance, $\mathrm{CpG}$ hypermethylation of the promoter region of glutathione S-transferase- $\pi$ gene (GSTP1) can be found in proliferative inflammatory atrophy and PIN and is present in $>90 \%$ of invasive carcinomas. ${ }^{3,14}$ Interestingly, other stress response genes, such as PTGS2 (which encodes for cyclooxygenase 2), show a similar pattern of epigenetic silencing during prostate cancer initiation and progression. ${ }^{15}$ Along these lines, reports suggest that LTF also undergoes epigenetic silencing by $\mathrm{CpG}$ hypermethylation in several types of cancer and in prostate cancer cell lines. ${ }^{16-19}$ Prior reports indirectly suggest that hypermethylation of this $\mathrm{CpG}$ island results in silencing of the LTF gene by demonstrating that LTF expression is restored by treatment with the demethylating agent 5-aza-2'-deoxycytidine in lung and prostate cancer cell lines. ${ }^{19,20}$ Furthermore, the observed LTF down-regulation or loss due to genetic mutation, allelic loss, or epigenetic silencing indicates that LTF may play an important role in many forms of cancer and may serve as a potential chemopreventative agent. ${ }^{19,21-23}$ Exogenously restoring LTF expression resulted in inhibition of proliferation and tumor growth in the human breast carcinoma cell line MDA-MB$231 .{ }^{24}$ In addition, treatment of four different human and neck cancer cell lines with LTF resulted in growth inhibition. ${ }^{25}$ In vivo, administration of bovine LTF inhibited the growth of intestinal polyps in mice and, in rats, reduced colon carcinogenesis after initiation. ${ }^{26-28}$

As prior reports of lactoferrin $\mathrm{CpG}$ island methylation in prostate cancer have been limited to analyses in $\mathrm{LNCaP}$ and LAPC 4 cells, ${ }^{19}$ and given the role of LTF as an immune modulator and potentially as a tumor suppressor, we comprehensively studied LTF expression and its pattern of epigenetic silencing in primary and metastatic prostate cancer. On the basis of our previous studies examining protein expression of LTF in radical prostatectomy specimens, ${ }^{4}$ we hypothesized that $L T F$ would be unmethylated but not expressed in normal benign prostate epithelial tissue and methylated and silenced in cancer. We further hypothesized that methylation of the $\mathrm{CpG}$ sites would begin in PIN and spread further throughout the $\mathrm{CpG}$ island of the LTF gene in cancer. To test these hypotheses, we determined the status of methylation of the LTF $\mathrm{CpG}$ island in normal benign prostate epithelial cells, $\mathrm{BPH}$, high-grade PIN, cancer, and local and distant metastases. In addition, we evaluated the status and cellular localization of LTF protein and mRNA expression in normal-appearing prostate, prostatic atrophy, PIN, cancer, and distant metastases.

\section{Materials and Methods}

\section{Tissue Sections}

Hematoxylin and eosin-stained slides from recent formalinfixed, paraffin-embedded radical prostatectomy specimens $(<2$ years old $)$ were reviewed by an experienced pathologist (I.K., J.A.B.-D.V., or A.M.D.M.); and two tissue blocks were selected from each case: one with invasive adenocarcinoma (herein referred to as tumor), high-grade PIN near $(<3 \mathrm{~mm}$ away) tumor, and benign; and one with high-grade PIN, benign, and no tumor on the block or on immediately adjacent blocks. From each block, five ( $7 \mu \mathrm{m}$ thick) sections were cut onto 4- $\mu \mathrm{m}$ PEN membrane slides (Leica Biosystems, Buffalo Grove, IL; catalog number 11600288) for laser-capture microdissection (LCM) and stored at room temperature until used for LCM. A sixth section was used for a hematoxylin and eosin stain for reference, and additional adjacent sections were cut onto glass slides and then stored at $-20^{\circ} \mathrm{C}$ until use for immunohistochemistry (IHC) or chromogenic RNA in situ hybridization (RISH).

\section{LCM and DNA Extraction}

Before LCM, the unstained sections on membrane slides were deparaffinized in xylenes for 10 minutes twice, then rehydrated through $100 \%$ then $70 \%$ molecular biology grade ethanol in molecular biology grade water. The slides were then counterstained in 1:4.5 Dako Mayer's Hematoxylin Lillie's modification (Agilent, Santa Clara, CA; catalog number S330930-2) in molecular biology grade water. Slides were then rinsed in molecular biology water and dehydrated through an ethanol series and xylenes, then air dried in a sterile hood. Hematoxylin and eosin stains of whole slides were scanned and annotated to identify regions of tumor, high-grade PIN, and benign normal-appearing epithelium. These areas were then isolated using a Leica LMD7000 system (Leica Microsystems, Buffalo Grove, IL) in the Sidney Kimmel Comprehensive Cancer Center Cell Imaging Core Facility. DNA from three of the cases was extracted, as previously described for LCM specimens. ${ }^{14}$ The remaining three cases were extracted using the QIAmp DNA FFPE Tissue Kit (Qiagen, Germantown, MD; catalog number 56404). DNA was quantified by $\beta$-globin real-time quantitative PCR using iQ SYBR Supermix (BioRad Laboratories, Hercules, CA; catalog number 1708880) 
with a known quantity of commercial white blood cell DNA (BioChain, Newark, CA; catalog number D1234148) as the standard curve. Primers used were as follows: forward, $5^{\prime}-$ GTGCACCTGACTCCTGAGGAGA-3'; and reverse, 5'CCTTGATACCAACCTGCCCAG-3'. Cycling conditions were as follows: $95^{\circ} \mathrm{C}$ for 3 minutes; and 40 cycles of $95^{\circ} \mathrm{C}$ for 30 seconds, $64^{\circ} \mathrm{C}$ for 30 seconds, and $72^{\circ} \mathrm{C}$ for 45 seconds.

\section{Bisulfite Conversion and PCR}

A diagram of all assays used in our LTF studies is shown in Supplemental Figure S1. Bisulfite conversion was done using the EZ DNA Methylation Gold Kit (Zymo Research, Irvine, CA; catalog number D5005), and converted DNA was amplified using either AmpliTaq Gold (ThermoFisher, Waltham, MA; catalog number N808241) PCR reagents or Hot MolTaq (Molzym, Bremen, Germany; catalog number P-080-0100). Primers used were bisLTF $(+)$ on the sense strand: forward, 5'-TTTTTTATGTGGGAAAGAGATTG$3^{\prime}$; and reverse, 5'-CAAACATAAAACTTATCTTCCTC$3^{\prime}$; and bisLTF (-) on the antisense strand: forward, $5^{\prime}-$ GGGGTAAAGTTTTGAATAAAGGGG- ${ }^{\prime}$; and reverse, 5'-AAAACCCAACTCCTATTCCTCCCCAT- $3^{\prime}$. Cycling conditions were as follows: $95^{\circ} \mathrm{C}$ for 2 minutes; $95^{\circ} \mathrm{C}$ for 30 seconds, $55^{\circ} \mathrm{C}$ for 30 seconds, and $72^{\circ} \mathrm{C}$ for 30 seconds for 45 cycles; and $72^{\circ} \mathrm{C}$ for 2 minutes. PCR products were separated onto a $1 \%$ agarose gel, and bands were extracted using a QIAquick Gel Extraction Kit (Qiagen; catalog number 28706). Extracted PCR products were cloned using a TopoTA cloning kit for sequencing with chemically competent Escherichia coli (ThermoFisher; catalog number K4575J10). DNA from clones was extracted using Chelex 100 Chelating Resin (Bio-Rad Laboratories, Hercules, CA; catalog number 1432832). This DNA was then amplified using AmpliTaq Gold and M13 primers: forward, 5'GTAAAACGACGGCCAG-3'; and reverse, 5'-CAGGAAACAGCTATGACC- $3^{\prime}$. Cycling conditions were as follows: $94^{\circ} \mathrm{C}$ for 2 minutes; $94^{\circ} \mathrm{C}$ for 30 seconds, $49^{\circ} \mathrm{C}$ for 30 seconds, and $72^{\circ} \mathrm{C}$ for 1 minute for 35 cycles; and $72^{\circ} \mathrm{C}$ for 10 minutes. PCR products were then purified using a QIAquick PCR Purification kit (Qiagen; catalog number 28106) and submitted for Sanger sequencing at the Johns Hopkins Genetic Resources Core Facility. Sequences were trimmed and aligned in Sequencher version 5.1 (Gene Codes Corporation, Ann Arbor, MI), and consensus sequences were then input to DNA Methyl Map version 2.4 [custom software developed by Kumar Balasubramanian (Panasys Inc.) and S.Y.] to map methylated/unmethylated CpGs. ${ }^{29}$ The number of sequences mapped from each case and area were as follows: Case 1, 9 benign, 8 PIN away, and 10 PIN near; Case 2, 2 benign, 4 PIN away, 7 PIN near, and 2 tumor; Case 3, 7 benign, 7 PIN away, 7 PIN near, and 6 tumor; Case 4, 3 benign, 6 PIN away, 5 PIN near, and 6 tumor; and Case 5, 2 tumor.
Combination of Methylated-DNA Precipitation and Methylation-Sensitive Restriction Enzymes (COMPARE-MS)

Locus-specific DNA methylation analyses were performed, as previously described, with minor modifications. ${ }^{30,31}$ Patient samples used in this study were described previously. ${ }^{15,29}$ In brief, DNA sample concentrations were determined by spectrophotometer and validated by quantitative real-time PCR. DNA samples were digested with AluI and HhaI (New England Biolabs, Ipswich, MA). Enrichment reactions containing $20 \mu \mathrm{L}$ of magnetic Tylon beads (Clontech, Mountain View, CA), $10 \mu \mathrm{g}$ of recombinant methyl-CpG binding domain protein 2 (MBD2; Clontech), and $200 \mathrm{ng}$ of unmethylated self-ligated pCR2.1 vector (Invitrogen, Carlsbad, CA) were assembled in enrichment buffer [ $4 \%$ glycerol, $1 \mathrm{mmol} / \mathrm{L} \mathrm{MgCl}_{2}, 0.5 \mathrm{mmol} / \mathrm{L}$ EDTA, $0.5 \mathrm{mmol} / \mathrm{L}$ dithiothreitol, $120 \mathrm{mmol} / \mathrm{L} \mathrm{NaCl}, 10 \mathrm{mmol} / \mathrm{L}$ Tris- $\mathrm{HCl}$ ( $\mathrm{pH} 7.4$ ), $0.2 \%$ Tween-20, and protease inhibitors] and incubated for 1 hour at room temperature. After immobilization of magnetic beads, the supernatants containing unbound MBD2 polypeptides were discarded; and digested DNA samples were diluted in $100 \mu \mathrm{L}$ of enrichment buffer and incubated with MBD2-coated beads for 12 hours at room temperature under gentle shaking. Beads and associated DNA complexes were then immobilized by magnetization and washed three times with enrichment buffer. Precipitated DNA containing methylated DNA fragments was eluted in water by heating to $95^{\circ} \mathrm{C}$ for 15 minutes. Eluted DNA was then subjected to quantitative real-time PCR using the IQ SYBR Green Supermix (Bio-Rad Laboratories, Hercules, CA; catalog number 1708880) using primers LTF_COMPARE_F (5'-AGTGGCAGAGCCTTCGTTT- $\left.3^{\prime}\right)$ and LTF_COMPARE_R (5'-ACCGGACACAGGGACCAA-3') (Supplemental Figure S1). Male white blood cell genomic DNA was in vitro treated with M.SssI (New England Biolabs; catalog number M0226S) to obtain a fully methylated control. Untreated male white blood cell DNA served as a negative control. For quantitative assessment of locusspecific methylation levels, Ct values of the samples of interest were normalized to $\mathrm{Ct}$ values of the positive control (SssI) and calculated methylation indexes (ranging from 0.0 to 1.0 ) were used to derive methylation heatmaps.

\section{TMA Data}

Two tissue microarray (TMA) sets were used for LTF IHC and RISH. The first was a 120 Case High Grade Race Disparity TMA from the Department of Defense Prostate Cancer Research Program (http://prostatebiorepository.org) that was enriched for higher-grade (Gleason grade group 3 to 5) cases. This TMA set included 60 cases each from African American and European American men matched on age ( \pm 3 years), grade, and stage. From each case, four cores tumor and four cores matched benign were selected for 
inclusion in the TMA. The second TMA included metastases from distant sites collected at autopsy from six patients on the patient's death from prostate cancer. Three cores were selected from each metastatic site across multiple metastatic sites for each case.

\section{IHC Data}

LTF IHC was performed using anti-lactoferrin antibody EPR4338 (Abcam, Cambridge, UK; lot GRG65110-7) at 1:600 concentration, diluted in Antibody Dilution Buffer (Roche, Indianapolis, IN; catalog number ADB250) for 45 minutes at room temperature. Antigen retrieval was done in a steamer for 25 minutes using citrate unmasking buffer (Vector Laboratories, Peterborough, UK; catalog number H-3300). Powervision + Rabbit from Leica Biosystems (Buffalo Grove, IL; catalog number PV6119) was applied for 30 minutes at room temperature. SIGMAFAST 3,3'-diaminobenzidine (Sigma-Aldrich, St. Louis, MO; catalog number D4293) was applied for 20 minutes at room temperature. Hematoxylin counterstaining was then performed. There are two main forms of LTF: a full-length secreted form and a form arising from transcription beginning at an alternative promoter site in the first intron, $\Delta \mathrm{LTF}$. Positive and negative controls for the LTF IHC assay were performed with the PC3 prostate cancer cell line transfected with expression vectors for a full-length secreted form of LTF or $\Delta$ LTF (Origene, Rockville, MD) (Supplemental Figure S2). It was also confirmed via Western blot analysis that the antibody does not cross-react with transferrin (Supplemental Figure S2). Intelectin-1/2 (ITLN1/2) IHC was performed on a Roche Discovery Ultra machine using an intelectin 1/2 antibody (Abcam; catalog number EPR 20311) at dilution 1:400 for 40 minutes. Antigen retrieval CC1 was applied for 48 minutes. Discovery Anti-Rabbit HQ HRP with AMP kit (Roche Diagnostics, Basel, Switzerland) was used for chromogenic detection. Positive and negative controls for the intelectin $1 / 2$ IHC assay are shown in Supplemental Figure S3.

\section{RISH Data}

RISH was performed on adjacent cuts (Tissue Sections) from the cohort using a human LTF probe (ACD, Newark, CA; catalog number 425101). RNA quality in all tissues was assessed using peptidylprolyl isomerase B mRNA probe (positive control; ACD; catalog number 313911). The ACD RNAscope 2.0 Sample Preparation for FFPE Tissue Kit (ACD; catalog number 320046) was used, with the following adjustments: slides were treated with Pretreat 2 for 15 minutes, then dipped twice in $1 \%$ Tween in deionized water before applying Pretreat 3 for 15 minutes at $40^{\circ} \mathrm{C}$. For detection, the RNAscope 2.0 HD Detection Kit (Brown) (ACD; catalog number 310035) was used. Positive and negative controls for the LTF RISH assay were performed with the PC3 prostate cancer cell line transfected with expression vectors for a full-length secreted form of $L T F$ or $\Delta L T F$ (Origene) (Supplemental Figure S2).

Image Analysis

Whole tissue slides were scanned at $20 \times$ objective with an Aperio ScanScope CS linear-array scanner (Aperio, Vista, $\mathrm{CA}$ ), and image analysis was performed using Aperio Image Scope focused on areas that were annotated for LCM. For TMAs, slides were scanned at $20 \times$ objective; and image analysis was performed on each TMA spot using TMAJ and FRIDA (http://tmaj.pathology.jhmi.edu, last accessed July 16, 2019). Hue, saturation, value (HSV) color space segmentation was used to define the brown (positive IHC/ RISH) and blue (hematoxylin) masks; metamasks were generated to combine the color and Lasso Masks for image analysis. Stroma, staining artifacts, and glands that did not correspond with the annotation diagnoses were excluded.

\section{Statistical Analysis}

Unless otherwise indicated, data were compared among groups by two-tailed $U$-test using GraphPad Prism Software version 7.01 (GraphPad Software, Inc., San Diego, CA). Values were considered statistically significant at $P<0.05$.

\section{Results}

Lactoferrin Methylation in Both Primary and Metastatic Prostate Cancer

The methylation status of LTF was determined in a series of organ donor prostate specimens, BPH specimens, benign and matched tumor specimens from radical prostatectomy, local lymph node metastases collected at radical prostatectomy, and distant metastases collected at rapid autopsy using COMPARE-MS, which has been previously extensively validated. ${ }^{30}$ Organ donor prostates that were entirely submitted for histology, and showed no evidence of benign or neoplastic prostatic disease on histologic examination, exhibited low to absent $L T F \mathrm{CpG}$ island methylation (Figure 1A). A series of benign tissues that were matched to primary tumor samples likewise had low levels of methylation. There were two exceptions of benign tissues that had high levels of methylation (Cases 21 and 23) (Figure 1A). On further examination of these benign tissues with a PIN4 stain (high-molecular-weight cytokeratin, p63, and racemase; data not shown), the area harvested from Case 21 was an area of BPH with regions suggestive of high-grade PIN and/or early infiltrating cancer and the area harvested from Case 23 contained regions suggestive of low- and highgrade PIN with regions of atypia and/or early infiltrating carcinoma. The methylation levels in BPH tissues were low to moderate, with two of five samples containing methylation higher than that of benign and organ donor samples (Figure 1A). In contrast, primary tumor samples showed 
high levels of methylation, with 19 of 21 primary carcinoma samples exhibiting methylation above that of the benign tissues (Figure 1A). The matched tumor samples generally showed much higher levels of methylation than their benign counterparts, with the exception of Cases 21 and 23, as noted (Figure 1A). Lymph node metastases samples also showed a range of methylation levels, with all samples having some level of methylation. Distant metastases recovered at autopsy from men who died from metastatic prostate cancer also showed high levels of methylation, with 24 of 28 samples exhibiting methylation above that of benign tissues. These results demonstrate that a $\mathrm{CpG}$ island involving the $L T F$ gene is frequently methylated in primary and metastatic prostate cancer. Analyses of prostate cancer The Cancer Genome Atlas data, ${ }^{32}$ obtained using cBioPortal, ${ }^{33}$ demonstrated an inverse correlation between $L T F$ methylation and mRNA expression (Figure 1B) and provided support for frequent methylation of the LTF CpG island in prostate cancer. These results for $L T F$ are in line with similar in silico analyses of known methylated genes in prostate cancer, such as GSTP1, PTGS2, and CD38. ${ }^{31}$

\section{LCM and Bisulfite Sequencing Confirm Progressive Hypermethylation of the Lactoferrin CpG Island in PIN and Prostate Cancer}

Bisulfite sequencing was performed on areas of benign normal-appearing (not atrophic, noninflamed, not low-grade
PIN), high-grade PIN, and prostate cancer isolated using LCM to determine the extent of LTF methylation in these histomorphologically defined lesions. Cancer, high-grade PIN, and benign epithelial cells were carefully microdissected to enrich for luminal epithelium without stromal components (Supplemental Figure S4). Because intra-acinar spreading of carcinoma can appear similar to PIN, ${ }^{34}$ PIN near tumor ( $<3 \mathrm{~mm}$ from tumor) was analyzed separately from PIN away from tumor (no tumor on block or adjacent blocks). Benign tissues showed variable, but little to no, methylation in most of the $21 \mathrm{CpG}$ sites examined, with the first $4 \mathrm{CpG}$ sites being the most likely to be methylated (Figure 2). PIN both near and away from tumor had methylation across all $21 \mathrm{CpG}$ sites in each case, with some cases having a high degree of methylation across all sites and others having low to moderate methylation at some $\mathrm{CpG}$ sites. Tumor was highly methylated across most of the $\mathrm{CpG}$ sites in all cases examined.

\section{A Comparison of LTF mRNA and Protein Levels in Relation to Methylation}

IHC staining for LTF protein and RISH for LTF mRNA were performed on adjacent sections of the slides used for LCM, shown in Figure 2, to determine the correlation between methylation and levels of mRNA and protein expression in the same lesions. Annotations were carefully drawn so as to perform image analysis only on the specific
A
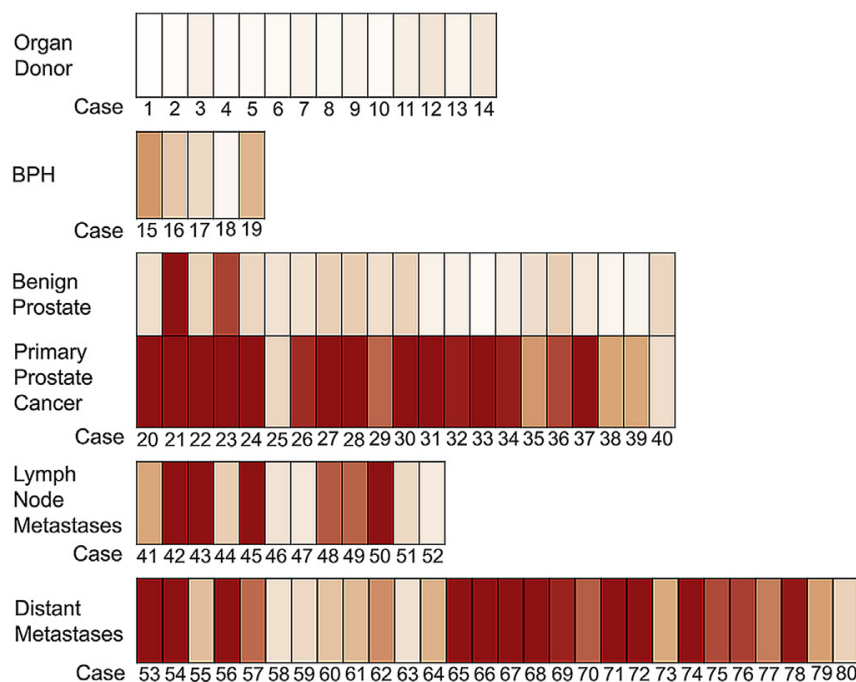

Methylation Index

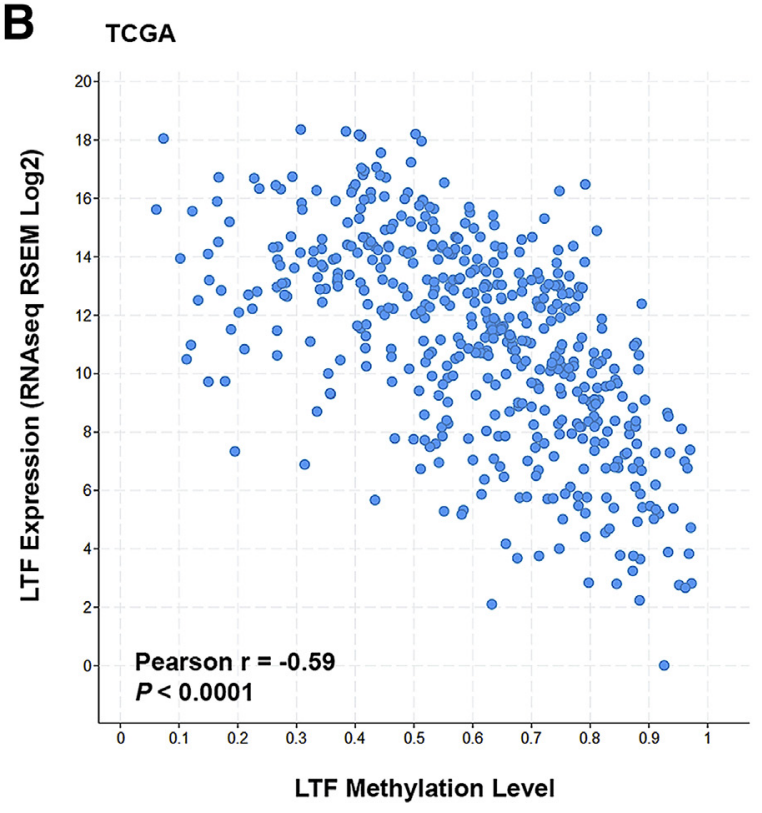

Figure 1 Combination of methylated-DNA precipitation and methylation-sensitive restriction enzymes (COMPARE-MS) demonstrates hypermethylation in primary and metastatic prostate cancer. A: Heat maps of COMPARE-MS results. White indicates no methylation, and dark red indicates $100 \%$ methylation. COMPARE-MS results demonstrate that organ donor and benign areas of prostates, obtained at radical prostatectomy, have low levels of methylation, whereas primary and metastatic prostate cancer has higher levels of methylation. Benign prostatic hyperplasia (BPH) has an intermediate level of methylation. B: In silico analysis of lactoferrin methylation versus mRNA expression using The Cancer Genome Atlas data from cBioPortal. LTF, lactoferrin; RSEM, RNA-seq by expectation maximization. 
glands that were also captured by LCM (Supplemental Figure S5). Positively stained (3,3'-diaminobenzidine; brown) pixels in the annotated regions were calculated as a percentage of the total positive pixels per annotated area. Percentage positive pixels was plotted against the average percentage methylation across the 21 targeted $\mathrm{CpGs}$ in the selected regions (Figure 2). As expected, benign noninflamed prostate tissue had little $L T F$ mRNA expression, despite lack of methylation (Figure 3A), as our previous study had demonstrated that LTF protein expression in benign regions is restricted to atrophy and inflamed epithelium. ${ }^{4}$ Likewise, high-grade PIN lesions both near and away from tumor and tumor samples were highly methylated and, therefore, expectedly negative for mRNA expression. Of interest, LTF protein expression was present in many of the samples, despite methylation status and a lack of mRNA expression (Figure 3, A-C). It was confirmed for all cases that lack of mRNA expression was not simply due to RNA degradation with a positive control stain for peptidylprolyl isomerase B (data not shown). The protein staining by LTF IHC is not attributed as falsepositive staining or a cross-reaction to another peptide/antigen because the IHC assay was validated with positive and negative controls whose expression was independently determined, and Western blot analysis of prostate tissue lysates produced only a single band at the correct size (Supplemental Figure S2). Furthermore, IHC staining with a separate LTF antibody (clone L3262; Sigma-Aldrich) showed an identical staining pattern to the Abcam antibody in areas that were negative for LTF by RISH (Supplemental Figure S6).
TMA Analysis Confirms Decoupling of Protein and mRNA Expression in PIN and Cancer

LTF IHC and RISH were performed on an additional 120 cases of matched benign and primary prostate cancer as well as six cases of metastatic samples from rapid autopsy using TMAs, and the results were quantified. For this analysis, the sum of intensities of all positive pixels for each TMA spot, where each spot was given a tissue diagnosis of benign (normal appearing), atrophy, PIN, or cancer, was calculated and the results were compared between tissue types for both IHC and RISH. The results of this analysis confirmed that, other than atrophy lesions, in which high levels of both mRNA and protein were present in the same regions, all of the other tissue types examined often demonstrated protein expression but no detectable mRNA expression (Figure 4, and Supplemental Figure S7). Interestingly, mRNA, but not protein, expression in normal prostate tissue was also significantly higher than cancer or distant metastases.

When the samples were assessed in relation to tumor grade, both normal and PIN from prostates with higher-grade tumors (Gleason score $\geq 4+3=7$; Gleason grade group 3 to 5) had significantly higher protein expression than those with lower-grade tumors (Gleason score 6 and $3+4=7$; Gleason grade group 1 to 2) (Supplemental Figure S8A). This trend was not observed for $L T F$ mRNA expression. There were no differences in LTF mRNA and protein expression when the tissue types were assessed by race, with the exception that LTF protein expression was significantly higher in atrophy from African American men versus European American men (Supplemental Figure S8B).
Heat map for sample methylation: $0 \%$

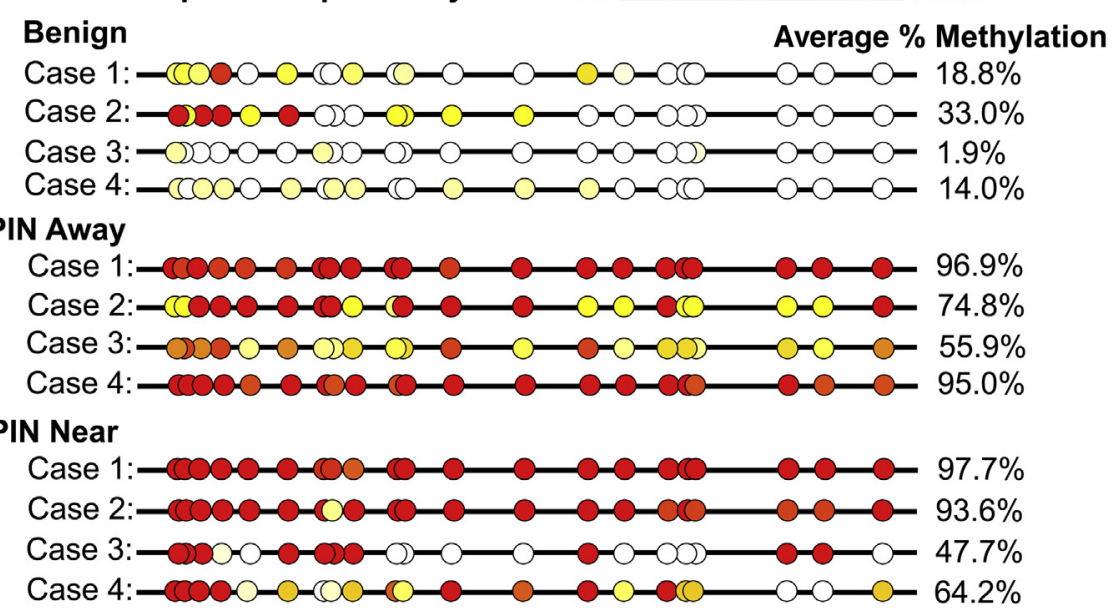

\section{Tumor}

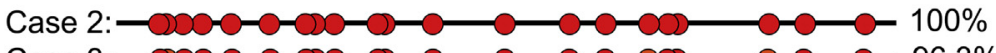

Case 3:- $-900 \%$

Case 4: $-\mathrm{COOO}-\mathrm{O}-\mathrm{OOO}-\mathrm{O}-\mathrm{O}-\mathrm{O}-\mathrm{O}-\mathrm{O}-\mathrm{CO}-\mathrm{O}-\mathrm{O}-\mathrm{O}-47.8 \%$

Case 5: $\rightarrow 000-00 \%$
Figure 2 Lactoferrin $\mathrm{CpG}$ island is hypermethylated in prostatic intraepithelial neoplasia (PIN) and prostate cancer. Clones obtained from bisulfite sequencing were analyzed with a bisulfite read mapper tool, Methyl Map. Each circle indicates average methylation across sequences from a case for each CpG site. White indicates unmethylated in all sequences, and red indicates methylated in all sequences. Benign samples generally had low methylation; however, PIN both near and away from cancer and cancer showed higher levels of methylation across all CPG sites. 

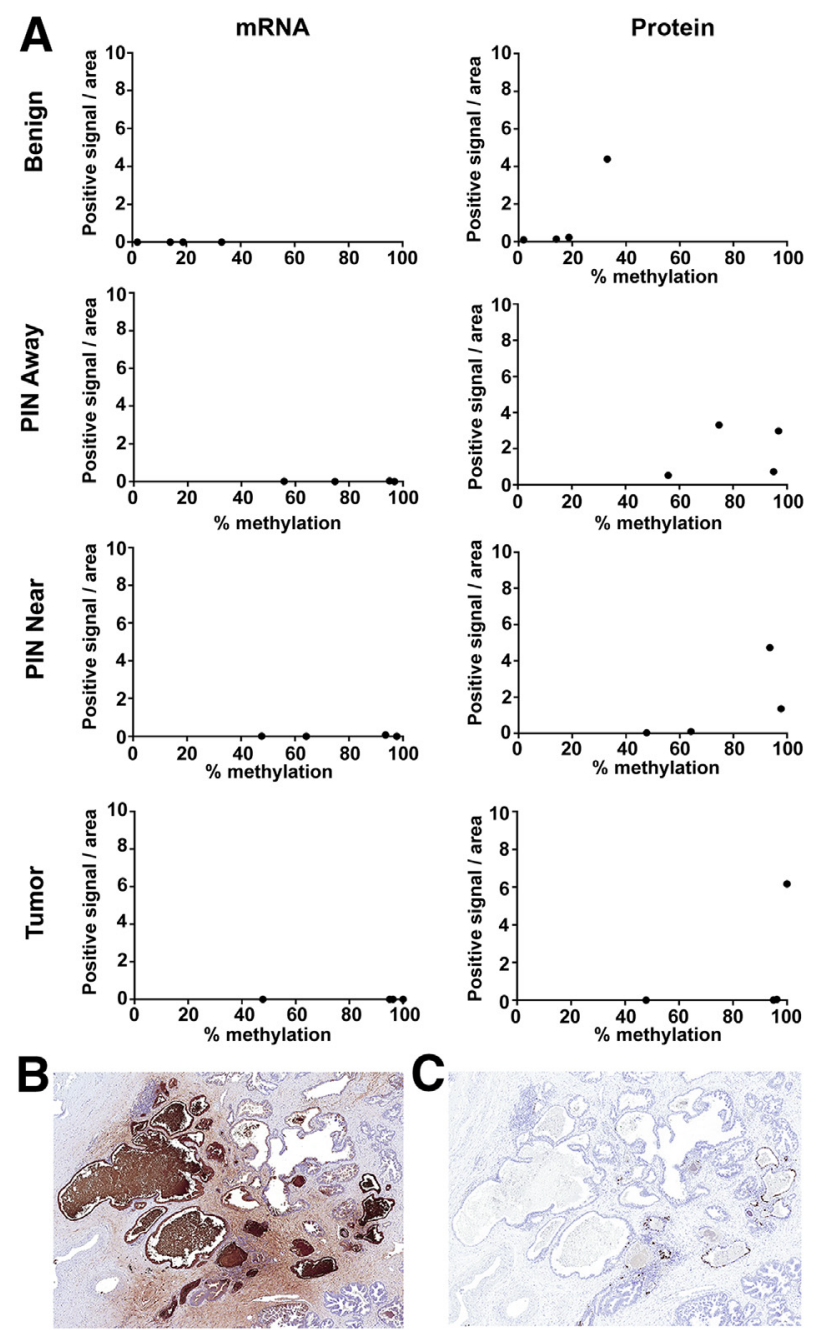

Figure 3 Lactoferrin (LTF) protein and mRNA do not correlate with each other or with methylation. A: Percentage positive pixels for immunohistochemistry (IHC) and RNA in situ hybridization (RISH) plotted against percentage methylation in sequences reveals no correlation between methylation and protein expression. B: LTF protein expression assessed via IHC shows abundant LTF protein. Adjacent section to image in C. C: LTF mRNA expression assessed via RISH shows little to no expression in areas with abundant protein in B. Original magnification, $\times 40$ (B and C). PIN, prostatic intraepithelial neoplasia.

Although distant metastases had the lowest LTF mRNA and protein expression of all tissue types assessed (Figure 4, $\mathrm{B}$ and $\mathrm{C}$ ), both mRNA and protein expression differed by metastatic site (Figure 5), with the highest protein expression in liver metastases and the highest mRNA expression in lung metastases. Unlike primary prostate cancer, metastatic cancer cells were rarely observed to express LTF protein. Rather, positive IHC and/or RISH signals were most likely from immune cells or benign cells (eg, hepatocytes) present in the metastatic niche (Supplemental Figure S9).

\section{Lactoferrin Receptor (ITLN-1) Expression Does Not Explain LTF mRNA/Protein Decoupling}

Because LTF is known to be a secreted protein that is readily taken up by epithelial cells via receptor-mediated endocytosis, ${ }^{7,35}$ we hypothesized that the protein observed via IHC, but not by RISH, was secreted elsewhere in the prostate and taken up by these cells. To explore this further, IHC was performed for ITLN-1/2, the canonical lactoferrin receptor using small intestine as a positive control (Figure 6 A). ${ }^{35,36}$ Intriguingly, in normal noninflamed benign prostate, basal epithelial cells were found to be positive for ITLN-1/2 (Figure 6B). This is in contrast to our observation that LTF-positive cells are luminal epithelial cells (Figure 4A and Figure 6C). In select regions of atrophy, and likely regions enriched with intermediate cells,${ }^{37}$ ITLN-1/2, $L T F$ mRNA, and LTF protein were all present in luminal epithelial cells (Figure 6C). ITLN-1/2 was not found to be present, however, in the cells with discordant expression of LTF mRNA and protein (Figure 6C).

\section{Discussion}

LTF has previously been shown to act as a tumor suppressor and to have antiproliferative effects on epithelial cells. ${ }^{17,38}$ LTF can also initiate innate immune responses, as well as protect against the harmful effects of inflammation. ${ }^{8-10,39-41}$ This multifunctionality makes LTF a particularly interesting protein in cancers in which inflammation plays a role, such as prostate cancer. In prostate cancer, there is evidence for inflammation as a driver of tumorigenesis. ${ }^{1-3,13}$ Silencing of LTF may allow this inflammation to propagate. A previous IHC study found LTF expression in individual cells (often many of them staining positive) or in epithelial structures referred to as lacunae (consisting of regions now referred to as benign roman bridging architecture) in the normal central zone, but not in the peripheral zone, except during inflammation. ${ }^{12}$ This low level of expression in the normal central zone may help to protect against the development of prostatic diseases, such as BPH and cancer.

The region containing the $\mathrm{CpG}$ island methylation of the LTF regulatory region studied herein has been previously shown to be associated with LTF transcriptional silencing. ${ }^{19,20}$ Our results demonstrate that $L T F$ has low to absent $\mathrm{CpG}$ island methylation in benign prostate tissue. Although normal prostate cells do not express LTF, this is not due to $\mathrm{CpG}$ island hypermethylation; therefore, LTF is presumably inducible in response to inflammatory stimuli in benign cells. In contrast, multiple lines of evidence that the LTF CpG island is hypermethylated in prostate cancer cells in clinical patient samples and is associated with the absence of LTF mRNA have now been shown. In addition, this hypermethylation is also present in the putative precursor lesion, high-grade PIN, local lymph node metastases, and distant metastases from castration-resistant prostate cancer.

One important factor to consider is the level of enrichment in the LCM versus the COMPARE-MS cohorts. LCM produces a strong enrichment for the specific epithelium of interest. However, at least some infiltrating immune cells are 
A
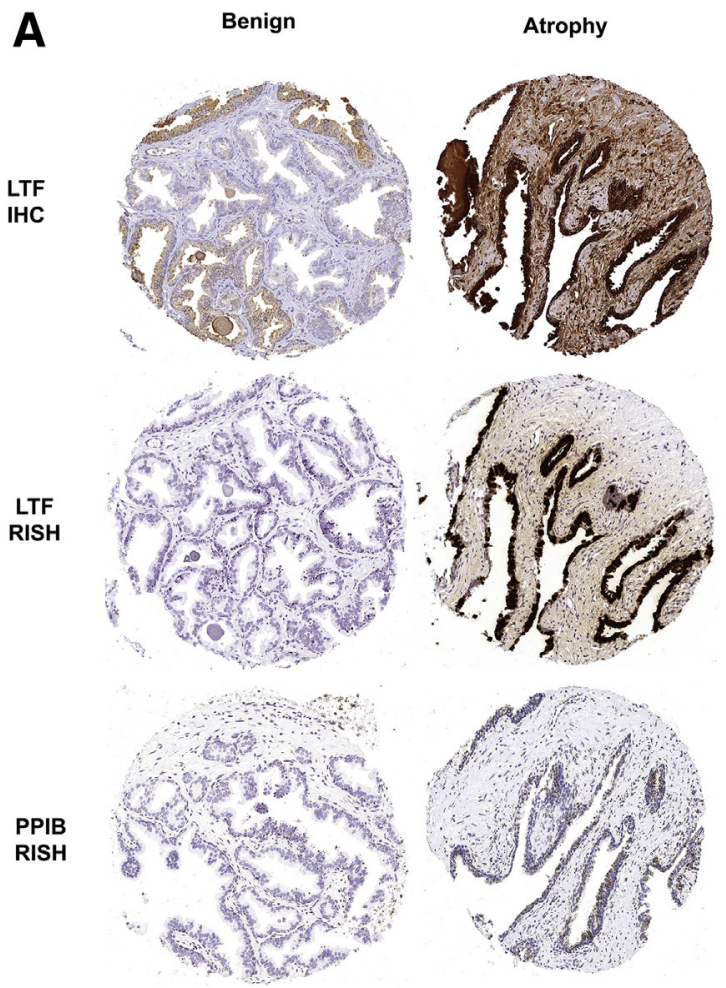

B

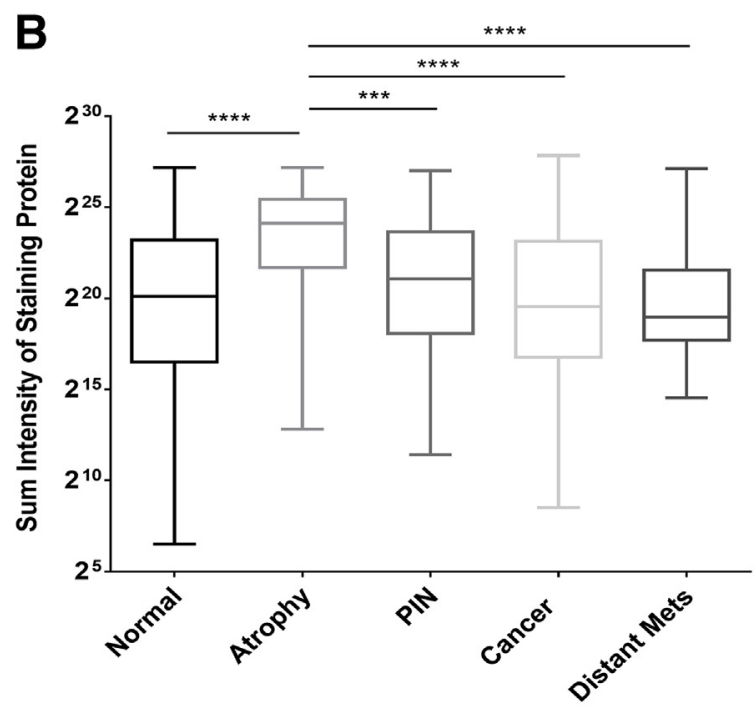

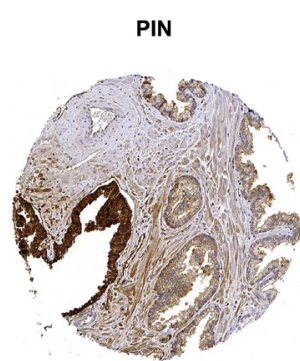
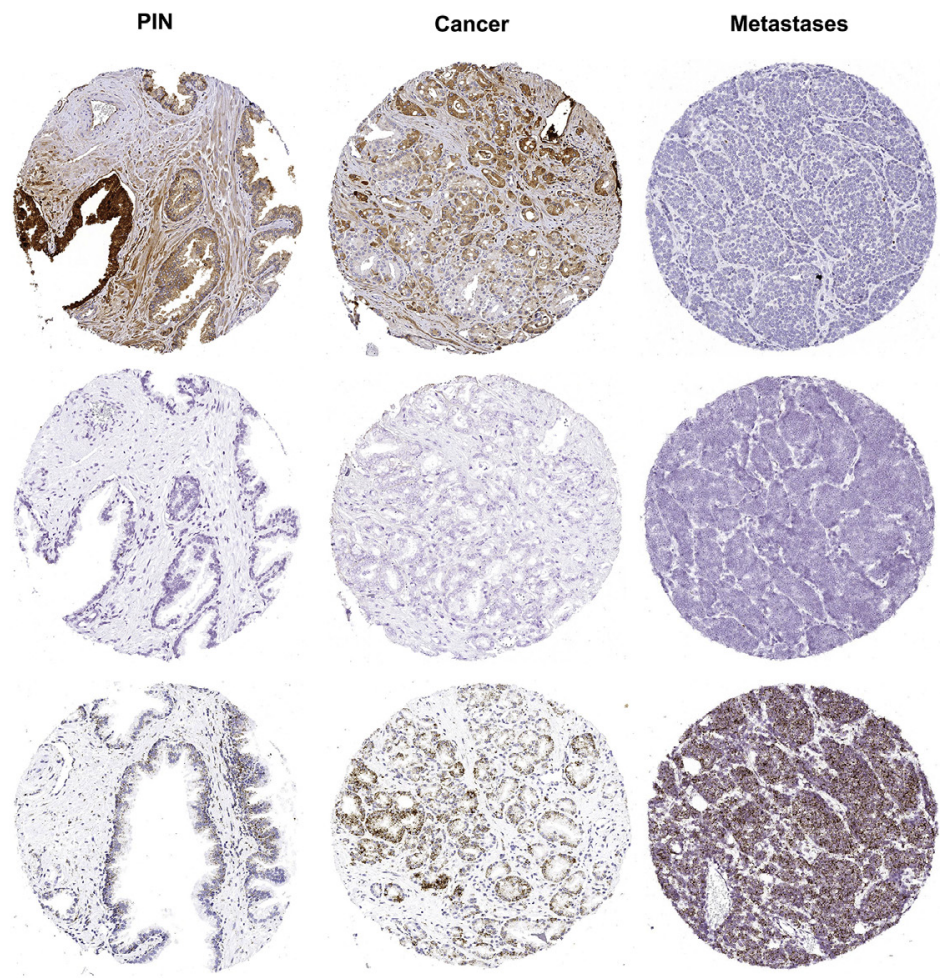

Figure 4 Lactoferrin (LTF) protein and mRNA expression do not correlate, as assessed with tissue microarrays. A: LTF protein is often present when there is no LTF mRNA expression. B and C: Log2 of total positive intensity shows that atrophy is the only cell type with protein at comparable levels (B) to mRNA (C). Atrophy was also the highest expressing lesion type for both protein and mRNA. C: For mRNA, normal prostate shows greater expression compared with primary or metastatic prostate cancer. ${ }^{*} P<0.05,{ }^{*} P<0.005,{ }^{*} * P<0.0005$, and ${ }^{*} * * * P<0.0001$. Original magnification, $\times 200$ (A). IHC, immunohistochemistry; PIN, prostatic intraepithelial neoplasia; PPIB, peptidylprolyl isomerase B; RISH, RNA in situ hybridization.

likely still present in these samples. Likewise, basal cells (in benign and PIN samples) as well as some stromal cells would have been collected alongside the luminal cells of interest. In the COMPARE-MS data set, these are larger areas of tissue that were selected to be enriched in the epithelium of interest (macrodissected), but there is no attempt to avoid intervening stroma such that there is much less stringent enrichment than in LCM. For example, the tumor areas generally had

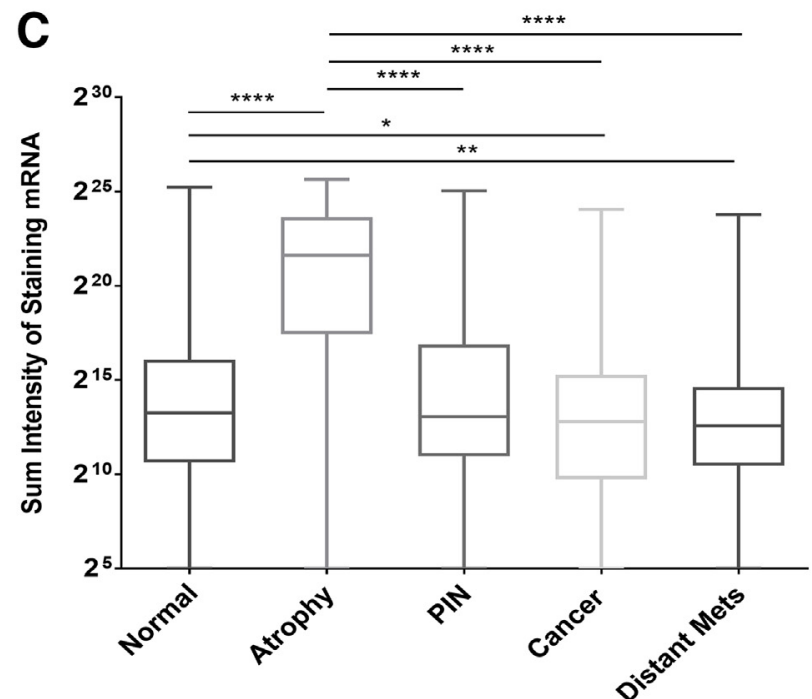

approximately $>70 \%$ to $90 \%$ tumor nuclei. This results in significant procurement of many nonepithelial cells and some epithelial cell types other than that of interest, which, in turn, would lead to underestimation of percentage methylation in cancer. In benign/normal-appearing regions, prostates from organ donors showed even lower levels of methylation compared with benign/normal-appearing regions from prostates with prostate cancer. In the COMPARE-MS sample set, 

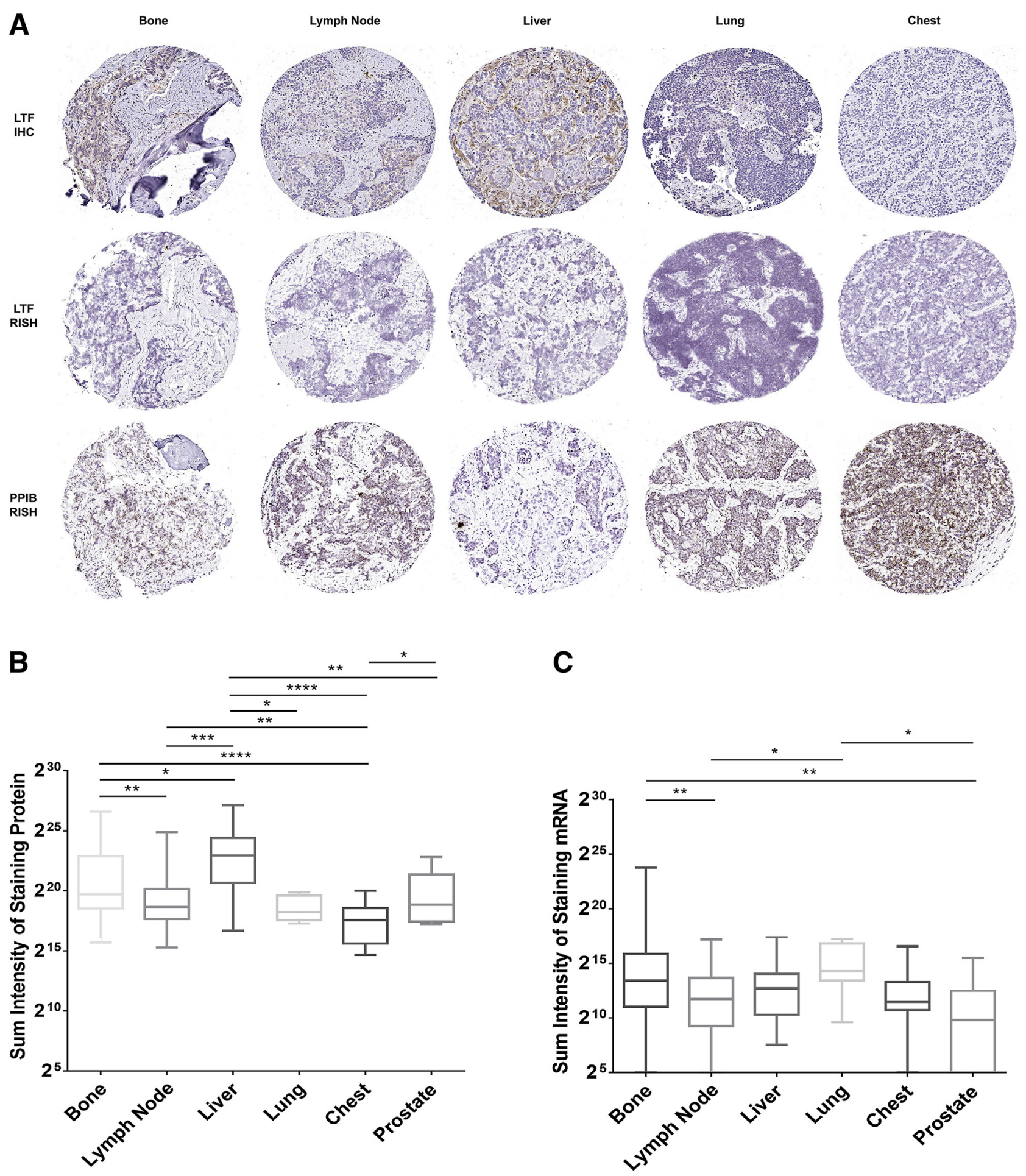

Figure 5 Distant metastases have varying low levels of lactoferrin (LTF) mRNA and protein that do not correspond. A: LTF protein and $m$ RNA vary by site and do not correspond. B and C: $\log$ of total positive intensity shows a wide variety in protein (B) and mRNA (C) by metastatic site. ${ }^{*} P<0.05,{ }^{* *} P<0.005$, $* * * P<0.0005$, and ${ }^{* * *} P<0.0001$. Original magnification, $\times 200($ A). IHC, immunohistochemistry; PPIB, peptidylprolyl isomerase B; RISH, RNA in situ hybridization.

because frozen sections were used for the diagnoses, and PIN is difficult to diagnose or exclude on a frozen section, PIN would not have necessarily been excluded from some of the benign areas; and many of the regions that were matched benign from prostate cancer cases may have had PIN admixed. The prostates from organ donors are from younger men, who likely had little, if any, PIN in their prostates. Because PIN had high levels of methylation in the LCM analyses, we hypothesize that the minimal levels of methylation seen in the benign tissue from cases with prostate cancer 

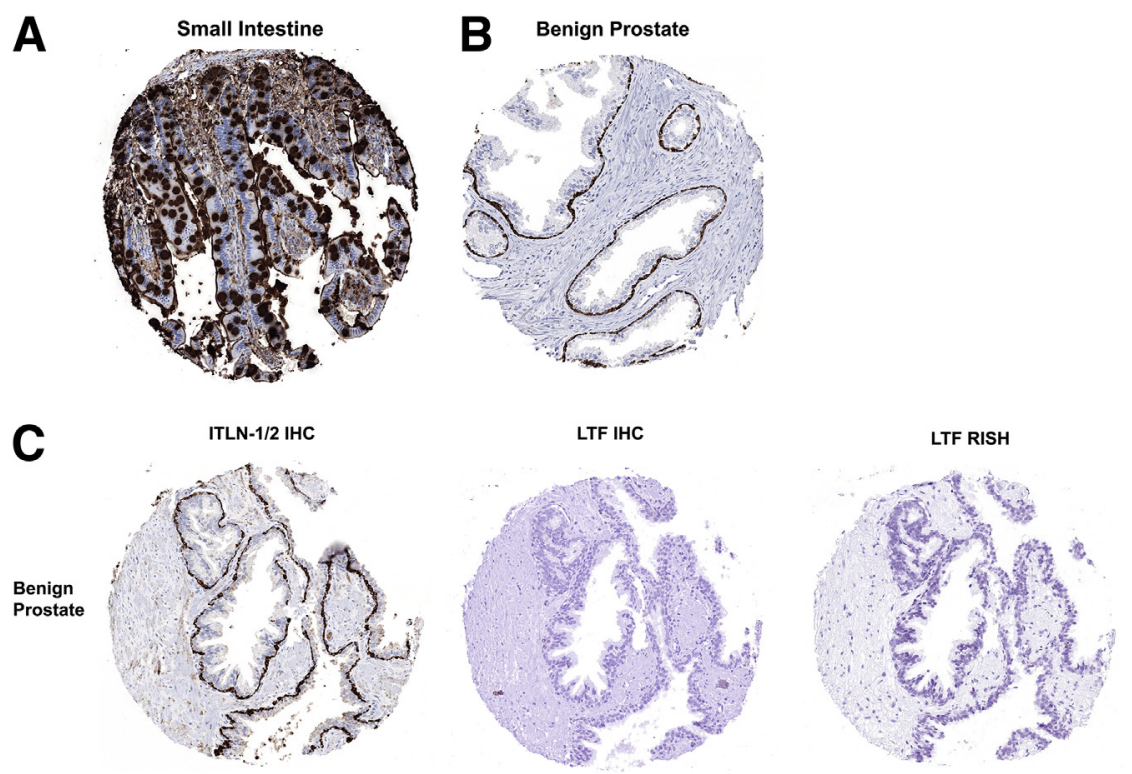
Figure $\quad 6 \quad$ Lactoferrin (LTF) receptor [intelectin-1/2 (ITLN-1/2)] expression does not explain discordant LTF mRNA and protein expres- sion. Immunohistochemistry (IHC) for intelectin, the canonical LTF receptor. A: Small intestine (positive control). B: ITLN-1/2 is localized to basal epithelial cells in normal, noninflamed prostate. C: Top panels: ITLN-1/2 is localized to basal epithelial cells and LTF mRNA and protein is absent in normal, noninflamed prostate. Middle panels: ITLN-1/2 staining is observed in luminal cells concurrent with LTF mRNA and protein in some regions of prostatic atrophy. Bottom panels: ITLN $-1 / 2$ is not expressed in cases where there is LTF protein expression but no mRNA. Example shown is an LTF IHC-positive region in cancer. Original magnification, $\times 200(\mathbf{A}-\mathbf{C})$. RISH, RNA in situ hybridization.

compared with from organ donor prostates is due, in part, to contamination with PIN. In our analyses of BPH samples, BPH was less hypermethylated than cancer, but still more methylated than in benign from organ donor prostates and more methylated than most benign from prostate cancer cases. BPH is not considered to be a precursor to prostate cancer development; however, there is still a proliferative component to this disorder, and at times regions of atypical adenomatous hyperplasia/adenosis, which is thought to be a precursor to low-grade transition zone cancers, are present in $\mathrm{BPH}$. The antiproliferative roles of LTF may be inhibitory to the proliferation seen in BPH, PIN, and cancer, if not silenced. The consistency of hypermethylation in cancer across cases supports the hypothesis that silencing of LTF may be essential to prostate cancer initiation. Furthermore, given the similar pattern of methylation in PIN and cancer in our study, we propose that this is further evidence that PIN and cancer share at least some highly similar somatic epigenetic alterations. This is also analogous to the methylation and silencing of the GSTP1 gene observed in prostate cancer. ${ }^{14,42}$

A discrepancy between LTF mRNA and LTF protein expression in the prostate was also discovered. Positive staining of atrophy with the LTF RISH probe as well as positive control staining with peptidylprolyl isomerase B markedly decreases the possibility of false-negative staining with the $L T F$ probe for $L T F$ mRNA present in the samples or that lack of staining is due to mRNA degradation, respectively. This leads to the conclusion that there are many cells and regions that have LTF protein, but not mRNA. Although mRNA is a necessary material in making protein, there are still several possible explanations for this; and several studies have shown poor correlation between mRNA and protein quantities. ${ }^{43}$ It is possible that the mRNA has been degraded 
not because of tissue age or quality, but that the LTF mRNA itself is targeted for degradation, or simply has a shorter halflife in the cell than the protein. Also, LTF is a secreted protein. Cells that are positive for $L T F$ mRNA may be producing and secreting LTF that is then taken up by cells that are negative for LTF mRNA but positive for protein. LTF is known to be present in prostatic fluid samples ${ }^{44}$ as well as secretions from multiple epithelial organs. ${ }^{45,46}$ Although the staining for the canonical LTF receptor ITLN-1/2 did not demonstrate that ITLN-1/2 is present in the cells that were positive for LTF protein (but not mRNA), this only eliminates the possibility of ITLN-1/2-mediated endocytosis. LTF is also able to bind to receptors other than ITLN-1/ $2 .^{36,47-49}$ Legrand et $\mathrm{al}^{50}$ found that LTF could bind to nucleolin and be endocytosed via vesicles in the recycling/ degradation pathway. Perhaps LTF is internalized via another receptor. Florian et $\mathrm{al}^{51}$ showed that inhibition of clathrindependent endocytosis largely, but not completely, blocked LTF uptake into cells. Therefore, LTF may be endocytosed by non-receptor-mediated means. LTF uptake by tumor cells may be due to its role as an iron transporter, as iron is required by cancer cells for proliferation. ${ }^{52}$ This requirement for extracellular uptake of LTF may be separate from the antitumor function of cellular expression and production of LTF within the cell.

Of interest, although the amount of $L T F$ mRNA in benign normal-appearing (not atrophy, noninflamed) regions was extremely low, benign regions displayed more $L T F$ mRNA than primary or metastatic cancer. LTF protein and mRNA expression varied widely between metastatic sites, but when sections are examined closely, positive cells are generally not cancer cells, but rather immune cells, likely from the metastatic site itself or from immune cells that have infiltrated the metastatic site via the circulation. LTF expression appears to be down-regulated in cancer areas, likely due to $\mathrm{CpG}$ island methylation.

In conclusion, we have herein demonstrated that $L T F-\mathrm{a}$ gene canonically known as an innate immune effector molecule - is likely silenced via $\mathrm{CpG}$ island methylation in both primary and metastatic prostate cancer. Although methylation of genes is variable between patients, genes that are methylated in multiple patients are enriched for cancer and development/differentiation-related pathways. ${ }^{53}$ The frequency at which the $L T F \mathrm{CpG}$ island is methylated across samples indicates that it is an important and conserved step in prostate cancer initiation. We, therefore, propose that $L T F$ may be considered as a tumor suppressor gene in prostate cancer.

\section{Acknowledgments}

We thank Lillian Dasko-Vincent, (Cell Imaging Core Facility, Sidney Kimmel Comprehensive Cancer Center) for assistance with LCM, and Jessica Hicks for assistance with immunohistochemistry.

\section{Supplemental Data}

Supplemental material for this article can be found at http://doi.org/10.1016/j.ajpath.2019.07.016.

\section{References}

1. Sfanos KS, De Marzo AM: Prostate cancer and inflammation: the evidence. Histopathology 2012, 60:199-215

2. De Marzo AM, Platz EA, Sutcliffe S, Xu J, Gronberg H, Drake CG, Nakai Y, Isaacs WB, Nelson WG: Inflammation in prostate carcinogenesis. Nat Rev Cancer 2007, 7:256-269

3. Nelson WG, De Marzo AM, DeWeese TL, Isaacs WB: The role of inflammation in the pathogenesis of prostate cancer. J Urol 2004, 172: S6-S12

4. Sfanos KS, Wilson BA, De Marzo AM, Isaacs WB: Acute inflammatory proteins constitute the organic matrix of prostatic corpora amylacea and calculi in men with prostate cancer. Proc Natl Acad Sci 2009, 106:3443-3448

5. Brock JH: The physiology of lactoferrin. Biochem Cell Biol 2002, 80: $1-6$

6. Gonzalez-Chavez SA, Arevalo-Gallegos S, Rascon-Cruz Q: Lactoferrin: structure, function and applications. Int J Antimicrob Agents 2009, 33:301.e1-301.e8

7. Legrand D, Pierce A, Elass E, Carpentier M, Mariller C, Mazurier J: Lactoferrin structure and functions. Edited by Bösze Z. In Bioactive Components of Milk. New York, NY: Springer New York, 2008. pp. 163-194

8. Legrand D: Overview of lactoferrin as a natural immune modulator. J Pediatr 2016, 173(Suppl):S10-S15

9. Kruzel ML, Zimecki M, Actor JK: Lactoferrin in a context of inflammation-induced pathology. Front Immunol 2017, 8:1438

10. Legrand D: Lactoferrin, a key molecule in immune and inflammatory processes. Biochem Cell Biol 2012, 90:252-268

11. Francis N, Wong SH, Hampson P, Wang K, Young SP, Deigner HP, Salmon M, Scheel-Toellner D, Lord JM: Lactoferrin inhibits neutrophil apoptosis via blockade of proximal apoptotic signaling events. Biochim Biophys Acta 2011, 1813:1822-1826

12. Reese JH, McNeal JE, Goldenberg SL, Redwine EA, Sellers RG: Distribution of lactoferrin in the normal and inflamed human prostate: an immunohistochemical study. Prostate 1992, 20:73-85

13. De Marzo AM, Marchi VL, Epstein JI, Nelson WG: Proliferative inflammatory atrophy of the prostate: implications for prostatic carcinogenesis. Am J Pathol 1999, 155:1985-1992

14. Nakayama M, Bennett CJ, Hicks JL, Epstein JI, Platz EA, Nelson WG, De Marzo AM: Hypermethylation of the human glutathione S-transferase- $\pi$ gene (GSTP1) CpG island is present in a subset of proliferative inflammatory atrophy lesions but not in normal or hyperplastic epithelium of the prostate: a detailed study using lasercapture microdissection. Am J Pathol 2003, 163:923-933

15. Yegnasubramanian S, Kowalski J, Gonzalgo ML, Zahurak M, Piantadosi S, Walsh PC, Bova GS, De Marzo AM, Isaacs WB, Nelson WG: Hypermethylation of $\mathrm{CpG}$ islands in primary and metastatic human prostate cancer. Cancer Res 2004, 64:1975-1986

16. Deng M, Zhang W, Tang H, Ye Q, Liao Q, Zhou Y, Wu M, Xiong W, Zheng Y, Guo X, Qin Z, He W, Zhou M, Xiang J, Li X, Ma J, Li G: Lactotransferrin acts as a tumor suppressor in nasopharyngeal carcinoma by repressing AKT through multiple mechanisms. Oncogene 2013, 32:4273-4283

17. Chea C, Miyauchi M, Inubushi T, Febriyanti Ayuningtyas N, Subarnbhesaj A, Nguyen PT, Shrestha M, Haing S, Ohta K, Takata T: Molecular mechanism of inhibitory effects of bovine lactoferrin on the growth of oral squamous cell carcinoma. PLoS One 2018, 13: e0191683 
18. Teng C, Gladwell W, Raphiou I, Liu E: Methylation and expression of the lactoferrin gene in human tissues and cancer cells. Biometals 2004, 17:317-323

19. Shaheduzzaman S, Vishwanath A, Furusato B, Cullen J, Chen Y, Bañez L, Nau M, Ravindranath L, Kim KH, Mohammed A, Chen Y, Ehrich M, Srikantan V, Sesterhenn IA, McLeod D, Vahey M, Petrovics G, Dobi A, Srivastava S: Silencing of lactotransferrin expression by methylation in prostate cancer progression. Cancer Biol Ther 2007, 6:1088-1095

20. Iijima H, Tomizawa Y, Iwasaki Y, Sato K, Sunaga N, Dobashi K, Saito R, Nakajima T, Minna JD, Mori M: Genetic and epigenetic inactivation of LTF gene at 3p21.3 in lung cancers. Int J Cancer 2006, 118:797-801

21. Yi HM, Li YC, Zhong RH: [Expression, genetic and epigenetic alterations of LTF gene in nasopharyngeal carcinoma cell lines]. Zhonghua Zhong Liu Za Zhi 2010, 32:729-733

22. Liu LH, Gladwell W, Teng CT: Detection of exon polymorphisms in the human lactoferrin gene. Biochem Cell Biol 2002, 80:17-22

23. Penco S, Caligo MA, Cipollini G, Bevilacqua G, Garré C: Lactoferrin expression in human breast cancer. Cancer Biochem Biophys 1999 , $17: 163-178$

24. Damiens E, El Yazidi I, Mazurier J, Duthille I, Spik G, BoillyMarer Y: Lactoferrin inhibits G1 cyclin-dependent kinases during growth arrest of human breast carcinoma cells. J Cell Biochem 1999, 74:486-498

25. Xiao Y, Monitto CL, Minhas KM, Sidransky D: Lactoferrin downregulates G1 cyclin-dependent kinases during growth arrest of head and neck cancer cells. Clin Cancer Res 2004, 10:8683-8686

26. Tsuda H, Sekine K, Ushida Y, Kuhara T, Takasuka N, Iigo M, Han BS, Moore MA: Milk and dairy products in cancer prevention: focus on bovine lactoferrin. Mutat Res 2000, 462:227-233

27. Tsuda H, Sekine K, Takasuka N, Toriyama-Baba H, Iigo M: Prevention of colon carcinogenesis and carcinoma metastasis by orally administered bovine lactoferrin in animals. Biofactors 2000, 12: 83-88

28. Ushida Y, Sekine K, Kuhara T, Takasuka N, Iigo M, Tsuda H: Inhibitory effects of bovine lactoferrin on intestinal polyposis in the Apc(Min) mouse. Cancer Lett 1998, 134:141-145

29. Yegnasubramanian S, Wu Z, Haffner MC, Esopi D, Aryee MJ, Badrinath R, He TL, Morgan JD, Carvalho B, Zheng Q, De Marzo AM, Irizarry RA, Nelson WG: Chromosome-wide mapping of DNA methylation patterns in normal and malignant prostate cells reveals pervasive methylation of gene-associated and conserved intergenic sequences. BMC Genomics 2011, 12:313

30. Yegnasubramanian S, Lin X, Haffner MC, DeMarzo AM, Nelson WG: Combination of methylated-DNA precipitation and methylation-sensitive restriction enzymes (COMPARE-MS) for the rapid, sensitive and quantitative detection of DNA methylation. Nucleic Acids Res 2006, 34:e19

31. Mottahedeh J, Haffner MC, Grogan TR, Hashimoto T, Crowell PD, Beltran H, Sboner A, Bareja R, Esopi D, Isaacs WB, Yegnasubramanian S, Rettig MB, Elashoff DA, Platz EA, De Marzo AM, Teitell MA, Goldstein AS: CD38 is methylated in prostate cancer and regulates extracellular NAD. Cancer Metab 2018, 6:13

32. Cancer Genome Atlas Research Network: The molecular taxonomy of primary prostate cancer. Cell 2015, 163:1011-1025

33. Gao J, Aksoy BA, Dogrusoz U, Dresdner G, Gross B, Sumer SO, Sun Y, Jacobsen A, Sinha R, Larsson E, Cerami E, Sander C, Schultz N: Integrative analysis of complex cancer genomics and clinical profiles using the cBioPortal. Sci Signal 2013, 6:p11

34. De Marzo AM, Haffner MC, Lotan TL, Yegnasubramanian S, Nelson WG: Premalignancy in prostate cancer: rethinking what we know. Cancer Prev Res 2016, 9:648-656

35. Akiyama Y, Oshima K, Kuhara T, Shin K, Abe F, Iwatsuki K, Nadano D, Matsuda T: A lactoferrin-receptor, intelectin 1, affects uptake, sub-cellular localization and release of immunochemically detectable lactoferrin by intestinal epithelial Caco-2 cells. J Biochem 2013, 154:437-448

36. Suzuki YA, Lopez V, Lonnerdal B: Mammalian lactoferrin receptors: structure and function. Cell Mol Life Sci 2005, 62:2560-2575

37. van Leenders GJ, Gage WR, Hicks JL, van Balken B, Aalders TW, Schalken JA, De Marzo AM: Intermediate cells in human prostate epithelium are enriched in proliferative inflammatory atrophy. Am J Pathol 2003, 162:1529-1537

38. Iigo M, Alexander DB, Long N, Xu J, Fukamachi K, Futakuchi M, Takase M, Tsuda H: Anticarcinogenesis pathways activated by bovine lactoferrin in the murine small intestine. Biochimie 2009, 91: $86-101$

39. Zimecki M, Mazurier J, Spik G, Kapp JA: Lactoferrin inhibits proliferative response and cytokine production of TH1 but not TH2 cell lines. Arch Immunol Ther Exp (Warsz) 1996, 44:51-56

40. Ye Q, Zheng Y, Fan S, Qin Z, Li N, Tang A, Ai F, Zhang X, Bian Y, Dang W, Huang J, Zhou M, Zhou Y, Xiong W, Yan Q, Ma J, Li G Lactoferrin deficiency promotes colitis-associated colorectal dysplasia in mice. PLoS One 2014, 9:e103298

41. Berlutti F, Schippa S, Morea C, Sarli S, Perfetto B, Donnarumma G, Valenti P: Lactoferrin downregulates pro-inflammatory cytokines upexpressed in intestinal epithelial cells infected with invasive or noninvasive Escherichia coli strains. Biochem Cell Biol 2006, 84: $351-357$

42. Brooks JD, Weinstein M, Lin X, Sun Y, Pin SS, Bova GS, Epstein JI, Isaacs WB, Nelson WG: CG island methylation changes near the GSTP1 gene in prostatic intraepithelial neoplasia. Cancer Epidemiol Biomarkers Prev 1998, 7:531-536

43. Maier T, Güell M, Serrano L: Correlation of mRNA and protein in complex biological samples. FEBS Lett 2009, 583:3966-3973

44. Manning ML, Williams SA, Jelinek CA, Kostova MB, Denmeade SR: Proteolysis of complement factors iC3b and C5 by the serine protease prostate-specific antigen in prostatic fluid and seminal plasma. J Immunol 2013, 190:2567-2574

45. Mason DY, Taylor CR: Distribution of transferrin, ferritin, and lactoferrin in human tissues. J Clin Pathol 1978, 31:316-327

46. Masson PL, Heremans JF, Schonne E: Lactoferrin, an iron-binding protein in neutrophilic leukocytes. J Exp Med 1969, 130:643-658

47. Takayama Y, Takahashi H, Mizumachi K, Takezawa T: Low density lipoprotein receptor-related protein (LRP) is required for lactoferrinenhanced collagen gel contractile activity of human fibroblasts. J Biol Chem 2003, 278:22112-22118

48. Rawat P, Kumar S, Sheokand N, Raje CI, Raje M: The multifunctional glycolytic protein glyceraldehyde-3-phosphate dehydrogenase $(\mathrm{GAPDH})$ is a novel macrophage lactoferrin receptor. Biochem Cell Biol 2012, 90:329-338

49. Qiu Z, Strickland DK, Hyman BT, Rebeck GW: $\propto 2$-Macroglobulin enhances the clearance of endogenous soluble $\beta$-amyloid peptide via low-density lipoprotein receptor-related protein in cortical neuron. J Neurochem 2002, 73:1393-1398

50. Legrand D, Vigié K, Said EA, Elass E, Masson M, Slomianny M-C, Carpentier M, Briand J-P, Mazurier J, Hovanessian AG: Surface nucleolin participates in both the binding and endocytosis of lactoferrin in target cells. Eur J Biochem 2003, 271:303-317

51. Florian P, Macovei A, Sima L, Nichita N, Mattsby-Baltzer I, Roseanu A: Endocytosis and trafficking of human lactoferrin in macrophage-like human THP-1 cells. Biochem Cell Biol 2012, 90: 449-455

52. Pfeifhofer-Obermair C, Tymoszuk P, Petzer V, Weiss G, Nairz M: Iron in the tumor microenvironment-connecting the dots. Front Oncol 2018, 8:549

53. Aryee MJ, Liu W, Engelmann JC, Nuhn P, Gurel M, Haffner MC Esopi D, Irizarry RA, Getzenberg RH, Nelson WG, Luo J, Xu J, Isaacs WB, Bova GS, Yegnasubramanian S: DNA methylation alterations exhibit intraindividual stability and interindividual heterogeneity in prostate cancer metastases. Sci Transl Med 2013, 5:169ra10 